\title{
Studying the effect of some botanical extracts of the Aveloz plant (Euphorbia tirucalli L.) on biological and productive characters of the mulberry silkworm (Bombyx mori L.)
}

\author{
El-Yamani Enas M. , Saad M.S.I., Hassan Eman M. \\ Sericulture Research Department, Plant Protection Research Institute, Agricultural Research Center, Dokki, Egypt
}

\begin{abstract}
The production of high quality and quantity of natural silk depends mainly on the nutritional status of the mulberry leaves fed to silkworms so, the healthy growth of silkworms and subsequently the economic traits are influenced largely by improving the mulberry leaf quality and feed efficiency of silkworm. The present study was an attempt to assess the effect of four extracts of Euphorbia tirucalli plant; acetone, petroleum-ether, ethyl alcohol and aqueous extracts on the biological characters, cocoon parameters and silk characters of the mulberry silkworm, Bombyx mori; the plant powder was soaked in petroleum-ether, acetone, ethyl alcohol and water serially. Each extract was used with three concentrations $(2.5,1.25$ and $0.625 \%)$ added to mulberry leaves. The schedule of application was applied since the beginning of the $5^{\text {th }}$ instar (every day first feed). Most concentrations of botanical extracts of Euphorbia tirucalli especially the concentrations $(2.5 \%$ and $1.25 \%$ ) increased significantly biological and technological characters of $B$. mori compared with the control group; larvae reared on mulberry leaves enriched with these concentrations of extracts especially acetone and aqueous extracts showed a significant increase in larval weight, cocooning percentage, emergence percentage, fecundity and pupal weight compared with the control, while, no significant differences were observed among means of the treatments in fertility percentage. On the same pattern, cocoon aspects (cocoon weight and cocoon shell weight) and silk characters (filament length, weight and size) enhanced significantly by rearing silkworms on fortified leaves with botanical extracts concentrations, compared with the control. While no significant variation was noticed among the means of silk ratio (\%). Conclusively, fortification of mulberry leaves with acetone, petroleum-ether, ethyl alcohol and aqueous extracts of $E$. tirucalli plant as nutritional additives improved the biotechnological characters of mulberry silkworm B. mori especially the acetone and aqueous extracts with increasing the concentrations.
\end{abstract}

Keywords: silkworm, Bombyx mori, mulberry leaves, nutritional additives, botanical extracts, Euphorbia tirucalli. 


\section{Introduction}

The silkworm Bombyx mori is a distinctive monophagous insect and derives almost all the nutrients required for its growth and development from the mulberry leaf itself (Nasreen et al., 1999). Nutrition of silkworm is the solitary factor which improves the growth, development, health, feed consumption and conversion of silkworm thereby improving the quality and quantity of silkworm cocoon production and productivity (Laskar and Datta, 2000; Waktole and Bhaskar, 2015). The healthy growth of the silkworm and ultimately the economic traits are influenced by the nutritional status of the leaves fed to silkworms (Krishnaswami et al., 1973; Ravikumar, 1988). Plants are the richest source of organic chemicals on world which influenced the life and behavior of different insects (Rajashekaragouda et al., 1997). Recently, many attempts have been made to secure mulberry leaves with botanical extracts to improve the mulberry leaf quality and feed efficiency of silkworm, which in turn help to increase cocoon production and silk quality. It has been shown that feeding of mulberry leaves to silkworm, treated with medicinal botanical plant extracts has varied influences on growth, development and reproduction (Hipparagi et al., 2001; Murugesh and Mahalingam, 2005). Previous studies have confirmed the effect of many extracts on various metabolic activities resulting in accelerated of silk cocoon formation and spinning (Shivakumar et al., 1995) and (Murugan et al., 1998) and increase in larval, cocoon as well as shell weight (Sridevi et al., 2003; Pardesh and Bajad, 2014a). Some plant extracts are feeding stimulants and improve the nutritional intake, growth, disease resistance/ tolerance of silkworm ultimately improving the cocoon traits (Bhaskar et al., 2004; Mahesha et al., 1999; Shubha, 2005). Euphorbia tirucalli L. commonly known as aveloz, is a plant indigenous to Africa and phytochemical screening of $E$. tirucalli reveals it, as a valuable medicinal plant with numerous medicinal properties. Many new drugs can be developed from E. tirucalli to control numerous diseases with no side effects as it is from natural source (Cataluna and Rates, 2015; Gupta et al., 2013; Priya and Rao, 2011). Moreover, aveloz has been reported to have antiviral and antimicrobial properties (Jurberg et al., 1985), E. tirucalli is reported to possess flavonoids, diterpenes, tannins, steroids and alkaloids as major phytochemcical compounds and possess also terpenes, alcohol eufol, alfaeuforbol, taraxasterol, E. tirucallol, cycloeuphornol, nhexacosanol, terpenic alcohol and trigliane (Fauconneau et al., 1997). The present study was therefore, undertaken to determine the effect of four extracts of E. tirucalli plant; acetone, petroleumether, ethyl alcohol and aqueous extracts on the biological characters, cocoon parameters and silk characters of mulberry silkworm, B. mori.

\section{Materials and methods}

This work was carried in the laboratories of Sericulture Research Department of Sharkkiya Governorate, Plant Protection Research Institute, Agriculture Research Center, Egypt.

\subsection{Insect culture and rearing conditions}

Diseases free laying eggs of $\mathrm{H} 1 \mathrm{x} \mathrm{KK} \mathrm{x}$ 
G2 x V2 silkworm hybrid were procured from the Sericulture Research Department, Plant Protection Research Institute (PPRI), Agricultural Research Center, Giza, Egypt. After hatching larvae were reared in the laboratory at $25 \pm 2^{\circ} \mathrm{C}$ and $75 \pm 5 \%$ relative humidity (Krishnaswami, 1978). The newly hatched larvae were fed on fresh clean mulberry leaves until the $5^{\text {th }}$ instar, which stage was used in our bioassays. 100 worms per replications were maintained.

\subsection{Mulberry variety}

Mulberry leaves variety; Morus alba var. Balady (native) was used as a source of feed.

\subsection{Disinfection of rearing room for silkworm rearing}

Rearing rooms, boxes and tools were thoroughly washed, treated with a disincentive solution (formalin 3\%) and left to dry before using. The whole boxes were kept clean and the paper sheets covered the bottom of the boxes were changed frequently.

\subsection{Collection and preparation of plant extracts}

The plant under investigation was originally collected from Zagazieg city, Sharkia governorate. Mature fresh leaves of Euphorbia tirucalli plant were collected, chopped into small pieces, placed in an oven, and dried at $50^{\circ} \mathrm{C}$. The leaves were then pulverized into plant powder using a small grinder. The plant powder was weighed and soaked in petroleum-ether, acetone, ethyl alcohol and water serially. The extracts were filtered and evaporated at $50^{\circ} \mathrm{C}$ using avocum rotary evaporator separately ( $\mathrm{Su}$ and Horvat, 1981). The dry extracts saved in refrigerator at $18^{\circ} \mathrm{C}$ until used. Euphorbia tirucalli plant extracts; acetone, petroleum-ether, ethyl alcohol and aqueous extracts, each extract was used with three concentrations $(2.5,1.25$ and $0.625 \%$ ).

\subsection{Schedule of application}

Mulberry leaves were washed, let to dry and were sprayed with plant extracts by using a small automizers and shade dried then fed to the silkworms starting from $\mathrm{V}$ instar onwards. The schedule of application was as follows: V instar (every day first feed). The control leaves were dipped in distilled water. For spinning purposes, the mature larvae were handily transferred to the mounges for cocoon building. Once the cocoon formation was completed, the larvae developed to pupae inside the cocoons. The resulted cocoons were harvested 7 days later, and then the cocoon numbers were counted to calculate the cocooning percentage for each replicate. Half number of the resulted cocoons of each replicate was oven dried at $80{ }^{\circ} \mathrm{C}$ and used to study the technological characters, while the other half of cocoons was used for the biological studies.

\subsection{Statistical analysis}

All data were analyzed using analysis of variance (ANOVA) and Least Significant Difference Test (LSD) was employed to 
compare the treatment means $(P=0.05)$ using the Costat program according to Snedecor and Cochran (1982).

\section{Results and Discussion}

\subsection{Biological characters}

The mean values of biological parameters of silkworm B. mori reared on mulberry leaves supplemented with different concentrations of botanical extracts of Euphorbia tirucalli plant are tabulated in Table (1). Significant increases were noticed in most concentrations compared with the control group.

\subsubsection{Larval weight $(g)$}

As shown in Table (1), weights of grown larvae exhibited a significant increase with most concentrations, especially the concentrations: $(2.5 \%)$ of aceton extract (3.95 gm) followed by (2.5\%) of water extract $(3.77 \mathrm{gm})$, then $(1.25 \%)$ petroleum ether extract and (2.5\%) ethyl alcohol extract recorded (3.65 and $3.60 \mathrm{gm}$ ) respectively, compared with the control (3.05 gm). The significant increase in larval weight might be attributed to the enhancement of bio-availability of nutrients for digestion and conversion by these plant extracts resulting in healthy growth of the silkworm. Moreover, the plant extracts positively influenced the healthy and vigorous growth of silkworms by stimulating the worms to feed more compared to the control group. These results are in agreement with
Waktole and Bhaskar (2015) who stated that, some plant extracts are feeding stimulants and improve the nutritional intake and growth of silkworm ultimately improving the cocoon traits. Similarly, $E$. tirucalli extracts may possess the compounds with antibacterial and antifungal properties that can be used as antimicrobial agents in the development of new drugs (Ajali et al., 2002; Annapurna et al., 2004). As the same trend, Pardesh and Bajad (2014b) reported that the moderate concentration $(2.5 \%)$ of Xanthium indicum L. extract had growth promoting effect in silkworm, B. mori. This is due to the physiological stimulation by plant extracts on silkworm larvae, leading to remarkable larval growth leading to increased food consumption and cocoon weight.

\subsubsection{Cocooning percentages (\%)}

Data represented in table (1) showed that, silkworm larvae fed on mulberry leaves fortified with the concentration $2.5 \%$ of acetone extract of E. tirucalli plant exhibited significantly the highest value in cocooning \% (100\%), followed by the concentrations $2.5 \%$ of petroleum ether extract and $1.25 \%, 0.625 \%$ of acetone extract which recorded (98.33\% for each), then (98\%) which recorded for the concentration $2.5 \%$ of water extract, compared with $(82 \%)$ for the control. This improvement in cocooning $\%$ could be due to the biochemical constituents of the plant extracts and the influence of the nutrients in the feed supplied which is probably attributed to the stimulatory effect of the botanicals on protein synthesis in the silk gland during larval 
period. The present findings are in confirmation with those of Shivakumar et al. (1995) and Murugan et al. (1998) who observed the effect of many extracts on various metabolic activities resulting in accelerated of silk cocoon formation and spinning.

Table (1): The effect of Euphorbia tirucalli plant extracts on the biological characters of mulberry silkworm $B$. mori L.

\begin{tabular}{|c|c|c|c|c|c|c|}
\hline $\begin{array}{l}\text { Euphorbia tirucalli } \\
\text { Extracts }\end{array}$ & Conc. & $\begin{array}{c}\text { Larval } \\
\text { weight }(\mathrm{g})\end{array}$ & $\begin{array}{c}\text { Cocooning } \\
(\%)\end{array}$ & $\begin{array}{c}\text { Emergence } \\
(\%)\end{array}$ & $\begin{array}{c}\text { Fecundity } \\
\text { (egg|female) }\end{array}$ & $\begin{array}{c}\text { Fertility } \\
(\%)\end{array}$ \\
\hline \multirow{3}{*}{ Acetone extract } & $2.5 \%$ & 3.95 & 100 & 99.83 & 655 & 99.97 \\
\hline & $1.25 \%$ & 3.55 & 98.33 & 100 & 623 & 100 \\
\hline & $0.625 \%$ & 3.35 & 98.33 & 99.57 & 615 & 99.5 \\
\hline \multirow{3}{*}{ petroleum-ether extract } & $2.5 \%$ & 3.55 & 98.33 & 99.93 & 601 & 99.76 \\
\hline & $1.25 \%$ & 3.65 & 96 & 99.87 & 583 & 99.5 \\
\hline & $0.625 \%$ & 2.81 & 87 & 98.6 & 551 & 99.3 \\
\hline \multirow{3}{*}{$\begin{array}{l}\text { Ethyl alcohol } \\
\text { Extract }\end{array}$} & $2.5 \%$ & 3.60 & 95 & 99.9 & 591 & 99.67 \\
\hline & $1.25 \%$ & 2.77 & 94 & 98.67 & 579 & 98.63 \\
\hline & $0.625 \%$ & 2.94 & 94 & 98.37 & 575 & 99.17 \\
\hline \multirow{3}{*}{ Water extract } & $2.5 \%$ & 3.77 & 98 & 99.93 & 589 & 99.9 \\
\hline & $1.25 \%$ & 3.12 & 97 & 99.87 & 604 & 99.97 \\
\hline & $0.625 \%$ & 3.39 & 94 & 99.97 & 626 & 99.47 \\
\hline Control & & 3.05 & 82 & 97.03 & 505 & 97.47 \\
\hline $\mathrm{LSD}_{0.05}$ & & $0.389 * * *$ & $3.258 * * *$ & $0.635 * * *$ & $82.746 *$ & ns \\
\hline
\end{tabular}

\subsubsection{Emergence percentage (\%)}

The results as shown in Table (1) indicated that, all concentrations of the botanical extracts of E. tirucalli plant under investigation recorded significantly high emergence percentage, such as the concentration $1.25 \%$ of acetone extract and $0.625 \%$ of water extract $(100 \%$ and 99.97\%) respectively, also the concentration $2.5 \%$ of petroleum ether extract, water extract and ethyl alcohol extract recorded $(99.93 \%, 99.93 \%$ and 99.9\%) respectively, compared with control group (97.03\%). These findings are in accordance with Prasad et al. (2011) stated that, Acetone, and petroleum ether extracts of E. tirucalli were reported to possess antibacterial activity against several bacterial species and antifungal activity. As the same way,
Jyothi et al. (2008) and Parekh et al. (2005) opined that, aqueous extract of $E$. tirucalli was reported to carry antioxidant activity and Antibacterial activity against Staphylococcus and Bacillus sp.

\subsubsection{Fecundity of female moth (egg $\backslash$ female) and fertility percentage (\%)}

As illustrated in Table (1), the different concentrations of botanical extracts showed significant increases in means of fecundity compared with the control, especially the concentration $2.5 \%$ of aceton extract recorded (655 egg/female), while the control group recorded (505 egg/female). While no significant vaiation was observed among means of fertility $\%$ within different concentrations of botanical extracts. The results are in confirmity with the findings of Lall and 
Meyer (2000) suggested that, the presence of compounds in the aceton extract possessing lipophilic characteristics, these observed antimicrobial properties agree with its use in traditional medicine. Further, Murugan et al., (1998) noticed a strong correlation between the growth of silkworm and the silk production in the silkworm after the treatment of plant extracts. Also, Priyanka et al., (2014) reported that, treatment mulberry leaves with different amount of Aloe vera oil then feeding of the larvae of silkworm, Bombyx mori (L) resulted in elicitation better response of reproductive ability (Fecundity, Hatchability).

\subsection{Cocoon indices}

Cocoon indices represented the most important indices in silk production. Cocoon weight, cocoon shell weight, cocoon shell ratio and pupal weight were recorded in Table (2).

\subsubsection{Fresh cocoon weight (g)}

Obtained data in Table (2) cleared that larvae fed on mulberry leaves treated with different concentrations of the botanical extracts of E. tirucalli plant showed a significant increase in fresh cocoon weights, especially the concentrations $(2.5$ and $1.25 \%)$ of the acetone extract recording (1.786 and $1.734 \mathrm{~g}$, respectively), followed by the concentration $(1.25 \%)$ of both water and petroleum ether extracts which recorded (1.698 and $1.620 \mathrm{~g}$ ) respectively, exhibited the highest cocoon weights compared with $(1.284 \mathrm{~g})$ for the control group. This might be due to the fact that, the plant extracts contain many biochemical factors that contributed to the improvement of cocoon weight, and these results in line with the findings of Deshmukh and Khyade (2013) observed that, Aloe tonic treated mulberry leaves influence the cocoons, pupal and growth parameters of B. mori.

\subsubsection{Cocoon shell weight $(g)$}

Data tabulated in Table (2) cleared that, the fifth instar larvae treated with the tested concentrations of Euphorbia tirucalli plant extracts, resulted a significant increase in the cocoon shell weights of the resulted cocoons compared with the control $(0.260 \mathrm{~g})$ which considered the least shell weight among treatments. This improvement in shell weight in the different plant extracts may be due to increased nutritional efficiency of food which is utilized by the insect. These results are in line with Itokowa et al. (1989) and Wu et al. (1991), observed that the Whole Euphorbia tirucalli plant has afforded to contain $7.4 \%$ citric acid with some malonic, succinic acids, Terpenoids and sterols which represents in plants important sources of vitamins, steroid compounds.

\subsubsection{Cocoon shell ratio (\%)}

According to the results obtained in Table (2), most concentrations of the botanical extracts of E. tirucalli plant under investigation exhibited high silk ratio than control group with no significant variation among them. 
Table (2): The effect of Euphorbia tirucalli plant extracts on the cocoon parameters of mulberry silkworm $B$. mori L.

\begin{tabular}{llcccc}
\hline $\begin{array}{l}\text { Euphorbia tirucalli } \\
\text { Extracts }\end{array}$ & Conc. & $\begin{array}{c}\text { Fresh cocoon weight } \\
(\mathrm{g})\end{array}$ & $\begin{array}{c}\text { Cocoon shell weight } \\
(\mathrm{g})\end{array}$ & $\begin{array}{c}\text { Silk ratio } \\
(\%)\end{array}$ & $\begin{array}{c}\text { Pupal weight } \\
(\mathrm{g})\end{array}$ \\
\hline \multirow{3}{*}{ Acetone extract } & $2.5 \%$ & 1.786 & 0.366 & 20.5 & 1.395 \\
\cline { 2 - 6 } & $1.25 \%$ & 1.734 & 0.382 & 22.08 & 1.354 \\
\cline { 2 - 6 } & $0.625 \%$ & 1.698 & 0.368 & 21.66 & 1.324 \\
\hline \multirow{2}{*}{$\begin{array}{l}\text { petroleum-ether } \\
\text { extract }\end{array}$} & $2.5 \%$ & 1.576 & 0.368 & 23.34 & 1.202 \\
\hline \multirow{2}{*}{$\begin{array}{l}\text { Ethyl alcohol } \\
\text { Extract }\end{array}$} & $1.25 \%$ & 1.620 & 0.350 & 21.62 & 1.265 \\
\hline \multirow{2}{*}{ Water extract } & $0.625 \%$ & 1.452 & 0.324 & 22.30 & 1.126 \\
\hline & $1.5 \%$ & 1.582 & 0.344 & 21.71 & 1.230 \\
\hline Control & $1.25 \%$ & 1.434 & 0.334 & 23.27 & 1.100 \\
\hline LSD $_{0.05}$ & $0.625 \%$ & 1.478 & 0.264 & 17.83 & 1.206 \\
\hline
\end{tabular}

\subsubsection{Pupal weight $(g)$}

The results in Table (2) showed that, all treatments were effective significantly in increasing the pupal weights; the concentration $(2.5 \%)$ of acetone extract recorded the highest pupal weight $(1.395$ g) among all the treatments, while the least pupal weight recorded by the control group $(1.024 \mathrm{~g})$. The significant improvement in cocoon characters (cocoon weight, pupal weight, shell weight and cocoon shell ratio) could be due to improved appetite of silkworms becoming stronger and tolerant to diseases and increased nutritional efficiency of feed which is utilized by worms. The present findings are in accordance with the findings of Priya and Rao (2011) stated that, phytochemical screening of E. tirucalli reveals it as a valuable medicinal plant with numerous medicinal properties. It is reported to possess flavonoids, diterpenes, tannins, steroids and alkaloids as major phytochemcical compounds and possess also terpenes, alcohol eufol, alfaeuforbol, taraxasterol, E. tirucallol, cycloeuphornol, n-hexacosanol, terpenic alcohol and trigliane (Fauconneau et al., 1997). Thus, the broad-spectrum antimicrobial activity exhibited by E. tirucalli may be attributed to the various active constituents present in it, which either due to their individual or combined action, exhibit antimicrobial activity (Bhuvaneshwar et al., 2010).

\subsection{Technological aspects}

According to the technological aspects which is very important from the view of industry, results of this work revealed a significant increase in the filament characters as a result of rearing silkworm B. mori on mulberry leaves supplemented with different concentrations of the botanical extracts of Euphorbia tirucalli plant as in Table (3).

\subsubsection{Silk filament length $(\mathrm{m})$}

Data tabulated in Table (3) cleared that all 
tested concentrations of E. tirucalli plant extracts revealed a significant increase in silk filament lengths. The highest filament lengths were recorded (1297 and $1249 \mathrm{~m}$ ) for the concentration $(2.5 \%)$ of acetone and ethyl alcohol extracts followed by the concentration $(0.625 \%)$ of petroleumether extract $(1218 \mathrm{~m})$, compared with the control group $(895 \mathrm{~m})$. This might be due to more shell content of cocoon in respective treatments. This has been further confirmed by Bhuvaneshwar et al. (2010) reported that, the alcoholic extracts of leaves of E. tirucalli possess antimicrobial activity against clinical and lab isolates several kinds of bacteria and fungi. Furthermore, Padma and Ramani (2015) noticed that, the larval weight and all the economic characters increased due to application of $2 \%$ ethanolic extract of Ocimum sanctum along with mulberry leaves and concluded that Ocimum sanctum extract has growth promoting effect on silkworm, which helps to enhance the commercial qualities of silk and can be used in sericulture for yield improvement. Similarly, Pardeshi and Bajad (2014a) reported that, the nutritional supplementation with plant Amaranthus hybridus extract at the concentration of $0.5 \%, 1.0 \%, 1.5 \%$ and $2.0 \%$ may have beneficial effect on the growth of the silkworm $B$. mori and also increased the larval weight, cocoon weight, pupal weight, shell ratio and filament length by enhancing feed efficacy than control.

\subsubsection{Silk filament weight ( $g$ )}

Results represented in Table (3) showed that, there are high significant differences in silk filament weights among different concentrations under investigation; most tested concentrations revealed a significant increase in the weights of reeled silk filament compared with control $(0.243 \mathrm{~g})$. The higher weights were recorded for the concentration $2.5 \%$ of acetone extract $(0.380 \mathrm{~g})$ followed by the concentration $0.625 \%$ of aqueous extract $(0.338 \mathrm{~g})$.

\subsubsection{Silk filament size (dn)}

Statistic analysis of data revealed highly significant differences in silk filament size among different concentrations treatments. The highest means of filament size were recorded $(2.872,2.637 \mathrm{dn})$ for the treatment of mulberry leaves fortified with Euphorbia tirucalli acetone extract at concentration $1.25 \%, 2.5 \%$, and water extract at $2.5 \%$ and $1.25 \%$ (2.547 and $2.548 \mathrm{dn}$ ) respectively, compared with control which recorded (2.443 dn). While, the least mean of silk filament size was recorded $(1.874 \mathrm{dn})$ for the treatment with $0.625 \%$ ethyl alcohol extract of Euphorbia tirucalli plant. The improvement in the quality of the silk filament might be due to bio-availability of certain nutrients to the worms from the plant extracts, which might have enhanced the protein synthesis, particularly the fibroin synthesis in the posterior silk gland, which in turn might have influenced the filament characters. Similar kind of results has been obtained by Rajashekaragouda et al. (1997) reported that, the plant extracts phytochemicals could benefit sericulture by improving the silk yield of $B$. mori and commercial silk production. Further, 
Saravanan et al. (2011) observed the mulberry leaves at different supplementation of Cowpeas (Vigna concentrations enhanced the quality and unguiculata) aqueous extract with quantity of silk in Bombyx mori.

Table (3): The effect of Euphorbia tirucalli plant extracts on the silk filament characters of mulberry silkworm B. mori L.

\begin{tabular}{|c|c|c|c|c|}
\hline $\begin{array}{l}\text { Euphorbia tirucalli } \\
\text { Extracts }\end{array}$ & Conc. & $\begin{array}{l}\text { Filament } \\
\text { length }(\mathrm{m})\end{array}$ & $\begin{array}{c}\text { Filament } \\
\text { weight }(\mathrm{g})\end{array}$ & $\begin{array}{c}\text { Filament size } \\
(\mathrm{dn})\end{array}$ \\
\hline \multirow{3}{*}{ Acetone extract } & $2.5 \%$ & 1297 & 0.380 & 2.637 \\
\hline & $1.25 \%$ & 1028 & 0.328 & 2.872 \\
\hline & $0.625 \%$ & 1064 & 0.273 & 2.309 \\
\hline \multirow{3}{*}{$\begin{array}{l}\text { petroleum-ether } \\
\text { extract }\end{array}$} & $2.5 \%$ & 1169 & 0.308 & 2.371 \\
\hline & $1.25 \%$ & 1165 & 0.298 & 2.302 \\
\hline & $0.625 \%$ & 1218 & 0.280 & 2.069 \\
\hline \multirow{3}{*}{$\begin{array}{l}\text { Ethyl alcohol } \\
\text { Extract }\end{array}$} & $2.5 \%$ & 1249 & 0.328 & 2.363 \\
\hline & $1.25 \%$ & 1144 & 0.268 & 2.108 \\
\hline & $0.625 \%$ & 1071 & 0.223 & 1.874 \\
\hline \multirow{3}{*}{ Water extract } & $2.5 \%$ & 1060 & 0.300 & 2.547 \\
\hline & $1.25 \%$ & 1088 & 0.308 & 2.548 \\
\hline & $0.625 \%$ & 1198 & 0.338 & 2.539 \\
\hline Control & & 895 & 0.243 & 2.443 \\
\hline $\mathrm{LSD}_{0.05}$ & & $166.94 *$ & $0.056 * * *$ & $0.406^{* *}$ \\
\hline
\end{tabular}

Conclusively, Euphorbia tirucalli L. is a valuable medicinal plant with numerous medicinal properties. And the four medicinal botanical extracts of E. tirucalli (acetone, petroleum-ether, ethyl alcohol and aqueous extracts) under investigation may possess the compounds with antibacterial (Ajali et al., 2002), antifungal (Annapurna et al., 2004) properties and carry antioxidant activity (Parekh et al., 2005). So, according to the above results, it could be recommended that, fortification of mulberry leaves with botanical extracts of E. tirucalli as nutritional additives, especially acetone and aqueous extracts with increasing the concentrations were proved to be more efficient in rearing silkworm as it improved healthy growth, hence increased the viability of larvae and the biological characters ultimately enhancement of the cocoon productivity and the silk production.

\section{References}

Abd El-Latif, M. S., Esmail, A. M., Ahmed, M. F. and El-Sherbeiny, H. Y. (2011), "Variation, combining ability and biochemical genetic marker for drought tolerance in maize", Journal of Biological Chemistry and Environmental Sciences, Vol. 6 No. 4, pp. 143-166.

Ajali, U., Okide, G. B. and Chukwurah, K. C. (2002), "Antibacterial activity of Euphorbia poissoni pax extracts", Indian Journal of Pharmaceutical Sciences, Vol. 64 Vo. 5, pp. 477480.

Annapurna, J., Chowdary, I. P., Lalitha, G., Ramakrishna, S. V. and Iyengar, D. S. (2004), "Antimicrobial activity 
of Euphorbia nivulia leaf extract", Pharmaceutical Biology, Vol. 42 No. 2, pp. 91-93

Bhaskar, R. N., Sridevi, G., Devaiah, M. C. and Govindan, R. (2004), Evaluation of medicinal plant extracts based on cocoon and reeling parameters of silkworm, Bombyx mori L. $\left(\mathrm{CSR}_{2} x\right.$ $\mathrm{CSR}_{4}$ ), Proceedings of the National Seminar on Progress of Research on Disease and Pest Management, Chintamani, India, pp. 247-254.

Bhuvaneshwar Upadhyay, K. P. and Kumar, A. (2010): "Ethnomedicinal, phytochemical and antimicrobial studies of Euphorbia tirucalli L.", Journal of Phytology, Vol. 2 No. 4, pp. 65-77.

Cataluna, P. and Rates, S. (2015), The traditional use of the latex from Euphorbia tirucalli L. (Euphorbiaceae) in the treatment of cancer in South Brazil, Second World Congress on Medicinal and Aromatic Plants for Human Welfare: Pharmacognosy, Pharmacology, Phytomedicines, Toxicology, pp. 289-295.

Deshmukh, R. B. and Khyade, V. B. (2013), "Utilization of Aloe vera (L) herbal tonic for treating mulberry leaves before feeding the fifth instar larvae of silkworm, Bombyx mori L. (Race: PM × CSR2)", International Journal of Bioassays, Vol. 2 No. 1, pp. 281-285.
Fauconneau, B., Waaffo-Tequo, F., Hugnet, F., Barries, I., Decandit, A. and Merillon, J. M. (1997), "Comparative study of radical scavenger and antioxidant properties of phenolic compounds from Vitas vinfera cell culture using in vitro tests", Life Sciences, Vol. 16, pp. 2103-2110.

Gupta, N., Vishnoi, G., Wal, A. and Wal, P. (2013), "Medicinal Value of Euphorbia Tirucalli", Systematic Reviews in Pharmacy, Vol. 4 No. 1, pp. $40-46$.

Hipparagi, G. D., Rayar, S. G. and Karabhantanal, S. S. (2001), Field spray of extract of botanicals on mulberry and its effect on silkworm, Bombyx mori L., growth and development, Proceedings of the National Seminar on Mulberry Sericulture Research in India, KSSRDI, Bangalore, India, pp. $127-$ 132.

Itokowa, H., Ichihara, Y., Watanabe, K. and Takeya, K. (1989), "An antitumor principle from Euphorbialathyris", Planta Medica, Vol. 55 No. 3, pp. 271-272.

Jurberg, P., Cabral Neto, J. B. and Schall, V. T. (1985), "Molluscicide activity of the 'avelos' plant (Euphorbia tirucalli, L.) on Biomphalaria glabrata, the mollusk vector of schistosomiasis", Memorias do Instituto Oswaldo Cruz, Vol. 80, pp. 423-427. 
Jyothi, T. M., Shankariah, M. M., Prabhu, K., Lakshminarasu, S., Srinivasa, G. M. and Siddamsetty, R. (2008), "Hepatoprotective and antioxidant activity of Euphorbia tirucalli", Iranian Journal of pharmacology and Therapeutics, Vol. 7, pp. 25-30.

Krishnaswami, S. (1978), New technology of silkworm rearing, Bulletin 2, Central Sericultural Research and Training Institute, Central Silk Board, India, pp. 1-23.

Krishnaswami, S., Narasimhanna, M. N., Suryanarayan, S. K. and Kumarraj, S. (1973), Manual on Sericulture, Vol. 2, Silkworm Rearing Food and Agricultural Organization, Rome, Italy, pp. 131.

Lall, N. and Meyer, J. J. M. (2000), "Antibacterial activity of water and acetone extracts of the roots of Euclea natalensis", Journal of Ethnopharmacology, Vol. 72 No. 12, pp. 313-316

Laskar, N. and Datta, M. (2000), "Effect of alfalfa tonic and its inorganic ingredients on growth and development of silkworm Bombyx mori L. race Nistari", Environment and Ecology, Vol. 18: 591-596.

Mahesha, H. M., Rajashekhargouda, R. and Rayar, S. G. (1999), Effect of aqueous extracts of few botanicals with special reference to weeds on Bombyx mori L., Proceedings of the $18^{\text {th }}$ Congress of the
International

Sericultural

Commission, pp. 114-121.

Murugan K., Jayabalan, D., Senthilkumar, N., Senthil Nathan, S. and Sivaprakasam, N. (1998), "Growth promoting effect of plant products on silkworm", Journal of Scientific and Industrial Research, Vol. 57, pp. 740-745.

Murugesh, K. A. and Mahalingam, C. A. (2005), "Influence of Tribulus terrestris on the growth of silkworm, Bombyx mori L. and its impact on economic traits of cocoons", Progress of Research in Organic Sericulture and Seribyproduct Utilization, Vellore, pp. 151-155.

Nasreen, A., Cheema, G. M. and Ashfaq, M. (1999), "Rearing of silkworm, Bombyx mori L. on alternate food plants", Pakistan Journal of Biological Sciences, Vol. 2, pp. 843-845.

Padma, S. V. D. P. and Ramani, B. M. (2015), "Effect of Ocimum sanctum L. plant extract on the economic parameters of silkworm, Bombyx mori L.", Journal of Entomology and Zoology Studies, Vol. 3 No. 2, pp. 62-64

Pardesh, A. B. and Bajad, P. N. (2014a), "Effect of Xanthium indicum L. plant extract on the economic parameters of silkworm, Bombyx mori L.", International Journal of Recent Scientific Research, Vol. 5 
No. 3, pp. 683-686.

Pardesh, A. B. and Bajad, P. N. (2014b), "The effect of nutritional supplementation with Amaranthus hybridus L. extract on economic performance of mulberry silkworm, Bombyx mori L". Scholars Academic Journal of Biosciences, Vol. 2 No. 4, pp. :272-276.

Parekh, J., Jadeja, S. and Chanda, S. (2005), "Efficacy of aqueous and methanol extracts of some medicinal plants for potential antibacterial activity", Turkish Journal of Biology, Vol. 29, pp. 203-210.

Prasad, S., Swapna, N. L. and Prasad, M. (2011), "Efficacy of Euphorbia tirucalli (L) towards microbicidal activity against human pathogens", International Journal of Pharma and Bio Sciences, Vol. 2, pp. 12-18.

Priya, C. L. and Rao, K. B. (2011), "A review on phytochemical and pharmacological profile of Euphorbia tirucalli", Pharmacologyonline, Vol. 2, pp. 384-390.

Priyanka, S., Surendra, P. and Upadhyay, V. B. (2014), "Effect of Aloe vera oil influences the fecundity and hatchability of multivoltine mulberry silkworm (Bombyx mori Linn.) ", Pinnacle Biological Sciences, Vol. 2014, Article ID pbs_116, 7 Pages.

Rajashekaragouda, R., Gopalan, M.,
Jayaraj, S. and Natarajan, N. (1997), "Field performance of plant extracts on mulberry silkworm, Bombyx mori L.", Entomon, Vol. 22, pp. 235-238.

Ravikumar, C. (1988), "Western-Gharts as abivoltine region prospects, challenges and strategies for its development", Indian Silk, Vol. 26 No. 9, pp. 39-54.

Saravanan, $\quad$ M., Selvi, S., Veeranarayanan, M. and Nadanam, S. (2011), "Studies on the nutritional supplement of mulberry leaves with Cowpeas (Vigna unguiculata) to the silkworm Bombyx mori L. (Lepidoptera: Bombycidae) upon the activities of midgut digestive enzymes", International Journal of Nutrition, Pharmacology, Neurological Diseases, Vol. 1 No. 2, pp. 157-162.

Shivakumar, R. R., Raman, K. V. A., Reddy, K. V. V., Magadum, S. B., Datta, R. K. and Banerji, A. (1995), "Effect of phytoecdysteroids on larval and economic parameters of silkworm, Bombyx mori L.", Indian Journal of Sericulture, Vol. 34, pp. 46-49.

Shubha, K. (2005), Efficacy of medicinal plant extracts on stability and spread of BmNPV, M.Sc. Thesis, University of Agricultural Sciences, Bangalore, India.

Snedecor, G. W. and Cochran, W. G. (1982), Statistical Methods, Iowa 
State University Press, Iowa, USA.

Sridevi, G., Basker, R. N. and Devaiah, Wu, T., Lin, Y., Haruna, M., Pan, D., M. C. ( 2003), Influence of Shingu, T., Chen, Y., Hsu, H., medicinal plant extract on cocoon parameters of silkworm, Bombyx mori L. (Abstr), National conference on tropical Sericulture for Global competitiveness, CSRTI, Mysore, Karnataka, India. Nakano, T. and Lee, K. (1991), "Antitumor agents, Kansuiphorins A and B, two novel antileukemic diterpene esters from Euphorbia kansui", Journal of Natural Products, Vol. 54, pp. 823-829.

Su, H. C. F. and Horvat, R. (1981), "Isolation, identification and insecticidal properties of Piper nigrum amides", Journal of Agricultural and Food Chemistry, Vol. 29, pp. 115-118.

Waktole, S. G. and Bhaskar, R. N. (2015), "Fortification of mulberry leaves with medicinal botanical plant extracts effect on silkworm, Bombyx mori L. (PM $\times$ CSR2) (Lepidoptera: Bombycidae) larval growth and cocoon traits", Journal of Biological Sciences, Vol. 15, pp. 199-206. 